\section{G inecologia \\ A EXPOSIÇÃO FETAL À CABERGOLINA EM MULHERES COM HIPERPROLACTINEMIA PROMOVE RISCOS?}

Recente e interessante estudo observacional prospectivo ${ }^{1}$ conduzido por Colao et al. (2008) analisou a evolução de 329 gestações em mulheres tratadas com cabergolina desde 1994. Constataram 258 (78\%) nascimentos e 71 (22\%) abortos. Entre os 258 nascimentos, 250 (97\%) foram nativivos, quatro (2\%) natimortos e em relação aos casos restantes não havia referências. Dos 250 nativivos, 193 (77\%) tinham idade gestacional superior a 37 semanas, enquanto em $45(18 \%)$ a idade gestacional era inferior a 37 semanas. No tocante ao peso, $62 \%$ dos recém-nascidos exibiram valores entre $3 \mathrm{Kg}$ - 4 $\mathrm{kg}$. Anormalidades neonatais foram constatadas em 23 (9\%) dos recém nascidos, porém sem qualquer padrão, tanto no tipo como na severidade.

$0 \mathrm{~s}$ autores concluíram que a exposição fetal à cabergolina no início da gestação não induz a qualquer risco de aborto, parto prematuro ou malformação fetal.

\section{Comentário}

A hiperprolactinemia representa condição freqüente na prática clínica, acometendo $20-30 \%$ das jovens com amenorréia secundária e refletindo uma alteração no eixo hipotalâmico-hipofisário. C aracteriza-se pelo aumento persistente da prolactina sérica, decorrente de causas fisiológicas como gravidez, lactação, estímulo mamário, estresse, exercícios, uso de fármacos (antidepressivos, hipotensores, antipsicóticos) e causas patológicas como tumores hipofisários, lesões hipotalâmicas, hipotireoidismo primário e insuficiência renal crônica².

0 aumento da prolactina pode promover quadro de hipogonadismo em função da diminuição da liberação do $\mathrm{GnRH}$, com conseqüente redução nos pulsos de LH e FSH; dessa forma, a depender da severidade da hiperprolactinemia, podem surgir alterações menstruais (oligo e amenorréia), redução da densidade mineral óssea, galactorréia e infertilidade. $N$ os casos de prolactinomas, além das repercussões mencionadas, podem ocorrer outros sintomas decorrentes de fenômenos compressivos, como cefaléia, perturbações visuais e até hipopituitarismo.

Os agonistas dopaminérgicos - bromoergocriptina e cabergolina - são os fármacos indicados para tratar os quadros de hiperprolactinemia. N os casos de infertilidade conseqüentes à hiperprolactinemia, os agonistas dopaminérgicos são freqüentemente prescritos para reduzir as concentrações séricas de prolactina, o que permite corrigir desde sutis disfunções lúteas até quadros de anovulação crônica.
O s estudos clínicos revelam que a cabergolina, apesar de seu maior custo, é mais eficaz e apresenta menos efeitos colaterais do que a bromoercocriptina ${ }^{3}$; de fato, ao se comparar as taxas de gestação nas portadoras de microprolactino mas usuárias de cabergolina e bromoergocriptina, constatou-se nítida superioridade da cabergolina ( $83 \%$ contra $58 \%$ de gestações).

De forma geral, tanto a cabergolina quanto a bromoergocriptina são usualmente descontinuadas após a confirmação da gestação; no entanto, há situações, como nos casos de crescimento dos prolactinomas durante a gravidez que se impõe 0 uso dos ago nistas dopaminérgicos.

$\mathrm{N}$ esses casos, no entanto, as evidências desvelavam que a bromoercocriptina poderia ser mantida e ser a primeira escolha na gestação; tal fato se apoiava na análise de 1.410 gestações em usuárias desse agonista dopaminérgico, em que não se tinha evidenciado qualquer aumento no risco de malformações congênitas, abortos espontâneos, nem de alterações no desenvolvimento psicomotor de crianças acompanhadas até nove anos ${ }^{4}$.

$\mathrm{N} 0$ to cante à cabergolina, apesar de ela ser usada desde a década de 90 , os estudos pertinentes à sua segurança relacionada à exposição materna fetal ainda eram limitados e controversos ${ }^{5}$. Diante disso, emergia uma questão: afinal, cabergolina poderia ser usada durante a gestação?

0 s resultados do estudo de Colao et al., em 2008, contribuem de forma significativa para esclarecer esta questão e permite emitir uma mensagem final para os clínicos: Frente às prolactinomas que crescem durante a gestação, além da bromoergocriptina, a cabergolina passa a representar uma alternativa não só segura para o concepto e evolução da gestação, mas de alta eficácia, po is estudos anteriores em mulheres não grávidas já mostravam mais de $50 \%$ na redução do volume de macroprolactinomas em $96 \%$ de suas usuárias 2 .

José Mendes Aldrighi André Larissa Ribeiro Pires Antônio Henriques de França Neto AOKI T

Referências

1.Colao A, Abs R, Bárcena DG, Chanson P, Paulus W, Kleinberg DL. Pregnancy outcomes following cabergoline treatment: extended results from a 12-year observational study. Clin Endocrinol (0xf). 2008;68(1):66-71

2. Casanueva FF, M olitch ME, Schlechte JA, Abs R, Bonert V, Bronstein M D, et al. Guidelines of the Pituitary Society for the diagnosis and management of prolactinomas. Clin Endocrinol (0 xf). 2006;65(2):265-73.

3. Colao A, Di Sarno A, Cappabianca P, Briganti T, Tortora F, Auriemma RS, et al. Withdrawal of long-term cabergoline therapy for tumoral and nontumoral hyperprolactinemia. N Engl J Med. 2003;349(21):2023-33.

4. Robert E, Musatti L, Piscitelli G, Ferrari Cl. Pregnancy outcome after treatment with the ergot derivative, cabergoline. Reprod Toxicol. 1996;10(4):333-7.

5. Ricci E, Parazzini F, M otta T, Ferrari Cl, Colao A, Clavenna A, et al. Pregnancy outcome after cabergoline treatment in early weeks of gestation. Reprod Toxicol. 2002;16(6):791-3. 